\title{
Study on the High-performance Composite Wall Panel Envelop of Building and its Relevant Joint Construction
}

\author{
Yuxin $\mathrm{Gao}^{1}$, Baojun Cheng ${ }^{1}$, Pengfei Ma ${ }^{1}$, Boyuan $\mathrm{Shi}^{1}$, Shengrong Kang ${ }^{1}$, and Yulin $\mathrm{Tu}^{1 *}$ \\ ${ }^{1}$ China West Construction Academy of Building Materials, 610064, Chengdu in Sichuan Province, China
}

\begin{abstract}
Aiming at the general problems of envelop wall panel about the existing building, such as large surface density, low strength, poor service performance and high maintenance cost, a kind of high-performance composite wall panel is proposed in this paper. This wall panel takes high toughness cement-based composite material as shell and inorganic light thermal insulation material as core part. Its surface density equals to or is less than $70 \mathrm{~kg} / \mathrm{m} 2$, heat transfer coefficient equals to or is less than $1 \mathrm{~W} /$ $(\mathrm{m} 2 \mathrm{~K})$, and the minimum bending failure load equals to or is more than 8 times of wall panel weight. Combined with the characteristics of high-performance composite wall panel, the "removable connection system" and "beveled tongue and groove type" joint structure are proposed to realize the construction of high-performance composite wall panel without moisture, nondestructive free disassembly and green recycling.
\end{abstract}

\section{Introduction}

Green building and green construction are the inevitable development trend of China's construction. With the development of construction industrialization, many countries regard factory prefabrication and assembly construction of building components as important symbols of the building modernization and industrial transformation and upgrading [1]. From the perspective of development process, the first thing to the improvement of building quality and performance is to study the building envelope structure.[2].

The energy consumption caused by building walls accounts for a high proportion of the total energy consumption of the whole building. Our government has fully realized the importance and urgency of energy conservation of building, and has listed wall insulation as a key development area [3]. The research on thermal insulation and energy saving of building envelope shows that it is difficult to achieve energy saving, and the heat transfer coefficient is less than $1.3 \mathrm{~W} / \mathrm{m}^{2} \cdot \mathrm{K}$ with single material [4]. When a single material successfully save energy, its strength is difficult to meet the design requirements. For example, when the masonry structure reaches a certain thickness, it can meet the national energy-saving goal, but its strength is relatively low. American scholars representsd by B. Abediniangerabi proposed an innovative ultra-high performance fiber reinforced concrete (UHP-FRC) “sandwich" wall panel system, which can obtain larger thermal insulation space to potentially reduce building energy consumption by using the high strength and ductility of UHP-FRC, and they came up with a new idea to deal with the thermal bridge of connector[5]. El Kashef used aerated foam concrete as a sandwich insulation material instead of light foam plastics. It is proved that this kind of panel has outstanding performance and can guarantee its mechanical and thermotechnical properties[6].

The form and structure of modern buildings should be able to better meet the climate and environmental requirements, and the envelope components should meet the multiple applicability requirements of renewal, replacement and recycling. Based on these things, the writer1 puts forward a kind of high-performance composite wall panel envelop of building. Besides, combining with different building application scenarios and the requirements of high-value-added utilization of the whole building life cycle, the writer develops a new joint structure of high-performance composite wall panel based on recyclable utilization.

\section{Development of the High-performance Composite Wall Panel Envelop of Building}

\subsection{The Development Ideas of the High-performance Composite Wall Panel Envelop of Building}

The basic development ideas of high-performance composite wall panel system for building envelope can be summarized as follows: 
Using high-performance materials can save natural resources and realize the goal of " using less resources", thus green building materials could be achieved.

The structure is flexible and changeable, which can realize various combinations to meet the requirements of thermal insulation in different climatic zones.

The envelop system is relatively independent from the main structure. In the whole life cycle of the building, the envelop system may be updated and replaced according to the needs, and the materials, components and parts can be reused.

\subsection{Constructional Details of the High-performance Composite Wall Panel Envelop of Building}

According to the basic development idea of high-performance composite wall panel system in 1.1, the writer proposes a high-performance composite structure design with thin-walled large cavity shell and multi-functional core material. The ansys simulation analysis about the design bearing capacity of the number of ribs of large cavity wall panel is carried out, the concentrated bearing capacity of wall panels with different cavity structures (as shown in Figure 1.2.1) is shown in Table 1.2.1. When the concentrated load equals to $4.8 \mathrm{kn}$ (6 times the weight of the person), the optimal structure of the wall panel is the composite wall panel with two ribs and three cavities.

In order to increase the number of control group, two types of high-performance composite wall panel are designed. One is high-performance composite wall panel with ribbed shell (see Figure 1.2.2), the other is high-performance composite wall panel without ribbed shell (see Figure 1.2.3).

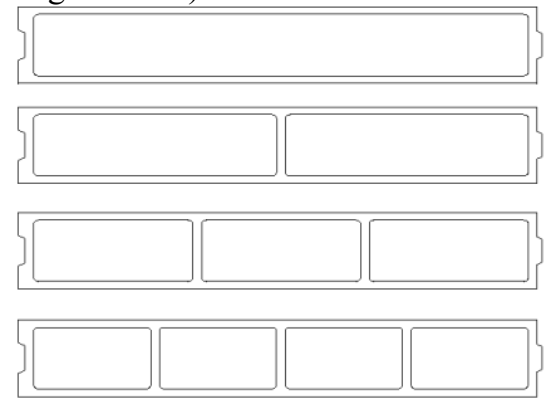

Figure 1.2.1 Wall panel structure with different number of ribs

Table 1.2.1 Concentrated bearing capacity of wallboard with different cavity structure

\begin{tabular}{ccccc}
\hline $\begin{array}{c}\text { cavities' } \\
\text { number }\end{array}$ & 1 & 2 & 3 & 4 \\
\hline $\begin{array}{c}\text { concentrated } \\
\text { load }(\mathrm{kN})\end{array}$ & 3.5 & 7.5 & 9.6 & 12.2 \\
\hline
\end{tabular}

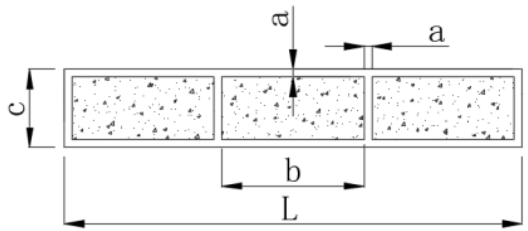

Figure 1.2.2 High performance composite wall panel with ribbed shell

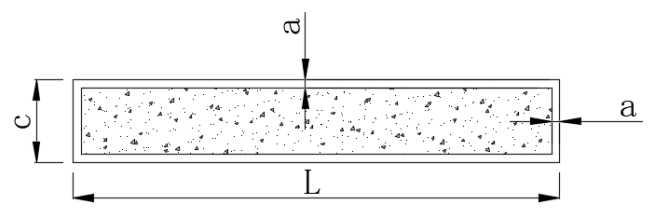

Figure 1.2.3 High-performance composite wall panel without ribbed shell

The high-performance composite wall panel is filled with light thermal insulation materials, not only reducing the weight of the whole prefabricated wall panel, but also increases the thermal resistance of the whole wall panel, thus enhancing the thermal insulation performance of the wall panel; At the same time, the high toughness cement-based composite material has high toughness and high durability. Compared with ordinary concrete, its impermeability, anti-carbonation capacity and bending resisitance can be increased by tens or even hundreds of times, so that the wall panel has better bending bearing capacity and durability.

\subsection{Preparation of the High-performance Composite Wall Panel Envelop of Building}

The preparation of high performance composite wall panel is shown in Figure 1.3.1

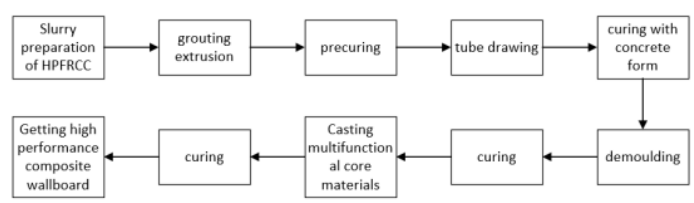

Figure 1.3.1 The preparation of high performance composite wall panel

\section{Performance Test}

\subsection{Mechanical Performance Test}

The mechanical properties of precast concrete wall panel only serves as enclosure structure. Generally, we only needs to test its bending resitance[8]. The bending test adopts the method of sand bag uniform surcharge loading, and the two ends of the specimen are simply supported, as shown in Figure 2.1.1; the test adoptes loading control method step by step, which can be seen in Figure 2.1.2. Except that the load holding time of the last-stage load is $20 \mathrm{~min}$, the load holding time of the rest stages is $10 \mathrm{~min}$. 


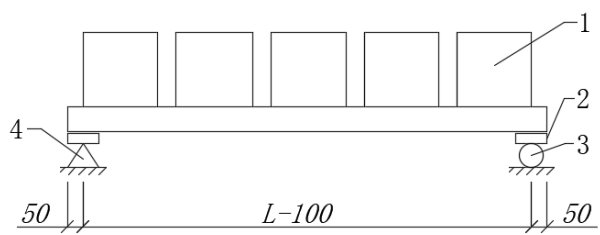

1 __loading weight; 2 __ plate (width $100 \mathrm{~mm}$, thickness $6 \mathrm{~mm} \sim 15 \mathrm{mmsteel}$ plate);3_roller support (diameter of steel column $60 \mathrm{~mm}$ );4_ fixed hinge support.

Figure 2.1.1 Loading diagram of bending test (loading weight)

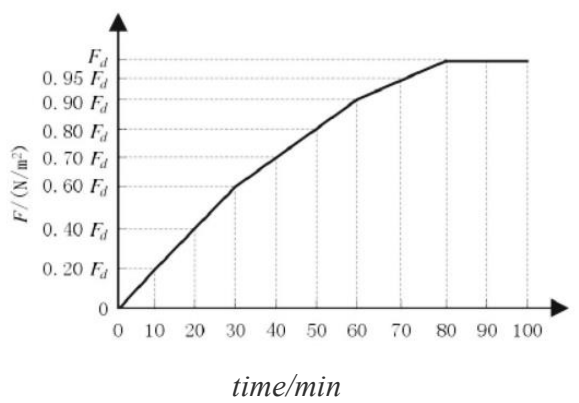

Figure 2.1.2 Loading system of bending test

In this test, the high-performance composite wall panel without ribs is adopted, its specification is $100 \mathrm{~mm}$ $\times 600 \mathrm{~mm} \times 2400 \mathrm{~mm}$, the thickness of shell thin wall $\mathrm{e}=$ $10 \mathrm{~mm}$, and the weight of wall panel is $70.20 \mathrm{~kg}$. The electronic dial indicator (as shown in Figure 2.1.3) is arranged at both sides and the middle position of both ends of the test piece. The deflection change of each position of the test piece during the step-by-step loading process is tested. The test results are shown in Figure 2.1.4. The electronic dial indicator (as shown in Figure 2.1.3) is arranged at both sides and the middle position of both ends of the test piece. The deflection change of each position of the test piece during the step-by-step loading process is tested. The test results are shown in Figure 2.1.4. Electronic dial indicatorS $(0.001 \mathrm{~mm}$ accuracy) are arranged on both sides of the middle of the specimen and at the center of both ends (as shown in Figure 2.1.3). And testing the deflection changes of each position of the test specimen in the progressive loading process. The test results are shown in Figure 2.1.4.

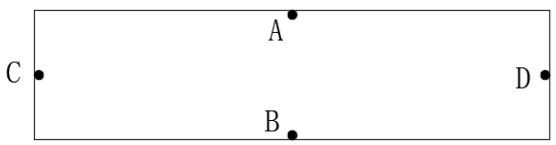

Figure 2.1.3 Layout of dial indicator for bending test

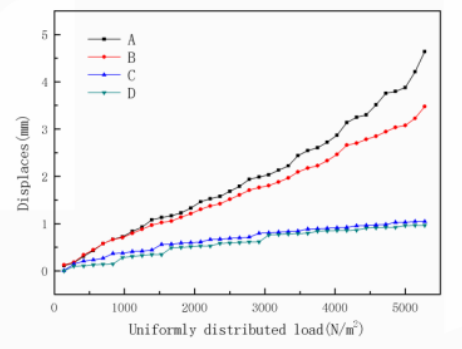

Figure 2.1.4 High performance composite wall panel without ribs - load displacement curve

When the maximum deformation of the position of longitudinal plate is $1.813 \mathrm{~mm}$ and the bending failure load is $4300 \mathrm{~N} / \mathrm{m} 2$; The ratio of bending failure load / slab weight is 9.12, which is much higher than the requirement in the Standard JGT169-2016 " general technical requirements of light weight used for building partition”. The ratio of bending failure load / plate weight is greater than or equal to $1.5 \mathrm{in}$ it.

\subsection{Thermal Performance Calculation and Verification}

This high-performance composite wall panel can meet the requirements of building energy-saving insulation performance without taking additional insulation measures.

(1) Relevant dimensions of specimen

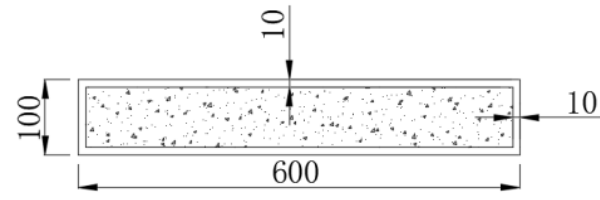

Fingure2.2.1 Cross-section map (unit:mm)

As shown in Fingure 2.2.1, the section size of the whole specimen is $800 \mathrm{~mm} \times 600 \mathrm{~mm} \times 100 \mathrm{~mm}$; the thickness of the side wall is $10 \mathrm{~mm}$, and the multi-functional core is made of foam concrete with dry density $140 \mathrm{~kg} / \mathrm{m} 3$, and its size is $800 \mathrm{~mm} \times 580 \mathrm{~mm} \times$ $80 \mathrm{~mm}$.

Defining the thermal conductivity of materials

Table 2.2.1 Thermal indexes of common building materials

\begin{tabular}{ccc}
\hline & & Thermal \\
Material name & Dry & conductivity $\lambda[\mathrm{W} /($ \\
& density $\rho\left(\mathrm{kg} / \mathrm{m}^{3}\right)$ & $\mathrm{m} \mathrm{K})]$
\end{tabular}

High toughness

1800

0.6

cement composite

Aerated and foam

concrete

0.046

Gypsum thermal

insulation mortar

$\begin{array}{ll}250 \sim 300 & 0.04\end{array}$

According to Table 2.2.1, we can see that the high toughness cement-based composite is similar to cement mortar, so its thermal conductivity is $0.93 \mathrm{~W} /(\mathrm{m} \cdot \mathrm{K})$; The multi-function core adopts foam concrete(dry density $140 \mathrm{~kg} / \mathrm{m} 3)$, so its thermal conductivity is $0.046 \mathrm{~W} /(\mathrm{m} \cdot \mathrm{K})$.

Thermal performance calculation and verification

According to the thermal performance calculation theory[9], the theat transfer coefficient of high performance composite wall panel foam concrete (dry core density $140 \mathrm{~kg} / \mathrm{m} 3)$ is $0.756 \mathrm{~W} /(\mathrm{m} 2 . \mathrm{K})$, which is much higher than the requirement in the Standard JGT169-2016 "general technical requirements of light 
weight used for building partition" . The heat transfer coefficient equals to or less than $1.5 \mathrm{~W} /(\mathrm{m} 2 \cdot \mathrm{K})$.

In order to verify the actual thermal resistance of the wall panel, the heat transfer coefficient of high performance composite wall panel is $0.796 \mathrm{~W} /(\mathrm{m} 2 \cdot \mathrm{K})$ by using the Heat Flow Meter method. The error between the theoretical value is $5.29 \%$, which is close to the experimental value.

\section{Research on Joint Construction of High Performance Composite Wall Panel Envelop of Building Based on Reusability}

\subsection{Joint Construction of High Performance Composite Wall Panel}

The weak links of sound insulation, waterproof and thermal insulation of various interior wall panels are mainly located at the joint between wall panels[10]. At present, constructing sound insulation and waterproof and material sound insulation and waterproof are the main means at home and abroad to deal with wall panel joint. And the sound insulation and water-proof methods mainly use transverse joints, high-low joints, and tongue and groove joints; the material sound insulation and waterproof methods mainly use PVC mortar, neoprene profile, EPDM and other caulking materials.

The joint structure between composite wall panels is shown in Figure 3.1.1: "beveled edge and groove" structure.
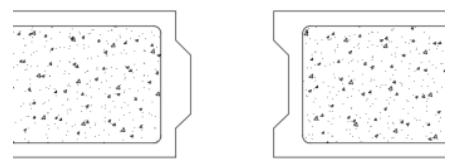

Figure 3.1.1 Design of wall panel groove

It can be seen from Figure 3.1.1 that both sides of the wallboard are designed with convex and concave edges. The elastic sealant strip is only set between the two plates (as shown in Figure. 3.1.2). And caulking them with elastic sealant at the seam.

It can be seen from Figure 3.1.2, several protrusions are arranged on the elastic sealant strip to leave a cavity between the elastic sealant strip and the wall panel, to achieve better sound insulation and prevent water climbing. This kind of construction can not only effectively ensure the wall panel flex and deform freely, but also prevent water seepage or creeping between the joints.

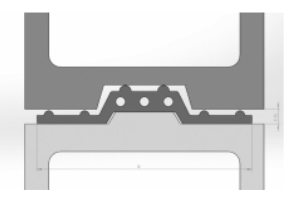

Figure 3.1.2 Sealing structure between wall panels

\subsection{Composite High Performance Wall Panels Connection System}

The high-performance composite wall panel envelop and structural base of the building are fixed by double “ L" positioning steel groove and removable connector (see Figure 3.2.1), as shown in Figure 3.2.2 and Figure 3.2.3. The specific methods are as follows: First, fixing the "L" positioning steel groove and rectangular steel beam on the floors and beams of the building; Second, using the removable connector and elastic wedge to fix the wall panel and the rectangular steel beam, in which the elastic wedge is used to fasten and adjust the relative position of the removable connector and the rectangular steel beam; Third, the second "L" positioning steel groove is used to limit the lower end of the wall panel.

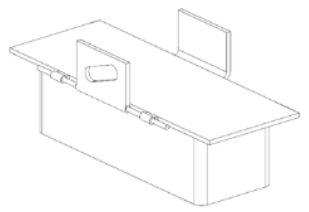

Figure 3.2.1 One of the detachable connectors for high performance composite wall panel

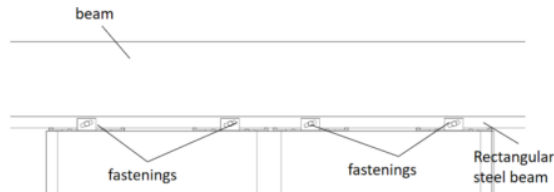

Figure 3.2.2 Diagram of the fixation between high performance composite wall panel and beam

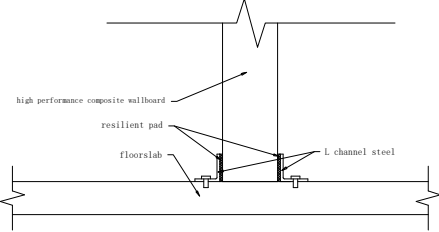

Figure 3.2.3 Diagram of the fixation between high performance composite wall panel and floor

\section{Conclusions}

This paper develops a multi adaptive high-performance composite wall panel system envelip of building. This system is relatively independent from the main structure, and its components and functional structural layer are relatively independent as far as possible. The components are standardized, modular and prefabricated. The structure is flexible and can realize various combinations. The test results show that the system components can meet the requirements of thermal insulation, sound insulation and waterproof after reasonable design, and various combinations can meet the needs of different climatic regions and different energy-saving design standards. The materials, components and components of the system have such characteristics as green environmental protection, rapid disassembly and recycling, which can greatly improve the function, performance, quality and service life of the 
building, and reduce its energy consumption.

\section{Acknowledgements}

The authors appreciate the financial support from the Research and Development Program of CSCEC(CSCEC-2019-Z-24), the Ministry of Housing and Urban Rural Development Research and Development Project(2019-K-049).

\section{References}

1. Xuan Qin,and Lei Jing,'Assessment and analysis of life cycle risk factors of green buildings: Based on questionnaire survey',China Civil Engineering Journal 08(2013):123-135.

2. Guo Cui, On the role of technology in building quality. Diss. Tsinghua University, 2012

3. Xiaoqian Qian,Yaotai Zhu,'Basic research on building energy consumption based on intermittent and partitioned energy consumption characteristics',China Civil Engineering Journal ,2010,43(S2):393-399

4. Hui Zhou,Hong Dong,Lixin Sun,et al.'Research on thermal performance optimization design of residential building envelope'[J]. Building Science, 2015, 31(10):105-111
5. B. Abediniangerabi,S.M. Shahandashti,B. Bell, et al. Building energy performance analysis of ultra-high-performance fiber-reinforced concrete (UHP-FRC) façade systems[J]. Energy \& Buildings, 2018, 174.

6. M. E1 Kashef, M. Abdel Mooty Investigating the use of autoclaved aerated concrete as an infill in reinforced concrete sandwich panels[J].Materials and Structures. 2014, 3(1).

7. Guodong Li, Wanjian Bi, Xiaoting Sun, et al. 'Study on Preparation and properties of physically foamed concrete'[J]. Bulletin of the Chinese Ceramic Society, 2017, 36(2):733-737

8. Jinfeng $\mathrm{Xu}$, Zhijing $\mathrm{Wu}$, Wenxiang Zhu,et al.Research on technology development and structural design of multiple adaptive wallboard exterior enclosure system[J],New Building Material, 2019, 46(03):88-92+97.

9. Junsong Wang, DEMARTINO Cristoforo, Yuyu Li, et al. 'Experimental study on thermal performance of light bamboo wood composite wall'[J]. Journal of Building Structures, 2019, 40(09):10-19.

10. Xun Zhong, Jinliang Wan, Qing Jiang, et al. 'Experimental study on seismic behavior of composite slab shear wall strengthened by horizontal joint'[J], Engineering Mechanics, 2018, 35(04):107-114. 